\title{
VIEWPOINT
}

\section{Placemaking for Coexistence: Child and Community Friendly Space HOUCH YGAMAANA Project, New Damietta, Egypt}

\author{
Insaf Ben Othmane Hamrouni, Omar Wanas \\ Ecumene Studio for Integrated Urban Planning and Sustainable Design \\ info@ecumene-studio.org
}

\begin{abstract}
HOUCH YGAMA'NA' is a participatory 'design and build' project piloted in 2014 that aims to create age and gender inclusive child-friendly spaces that foster children's imagination and enhance their physical, cognitive, emotional and social development. This paper focuses on the narrative of the project implemented in the Central Public Park of New Damietta, Egypt. The project entailed applying a set of urban and design practices centred around a socially engaging mobile installation all aiming to bring the users of the park from the Egyptian community and newly settled Syrian community together to collaborate in reshaping and developing their outdoor environment with the overarching aim of Integrating the local Syrian population in their host society and linking them to one of the active local associations in the area :Terre Des Hommes. The project is a manifestation of the socio-spatial dimension to placemaking where the produced public space is "both a product and producer of change"(Gottdiener M., Hutchison R., 20l I); as the created space is not only a collaborative effort by the local community, but also a tool within the overall process to achieve the project's overarching goal.
\end{abstract}

Keywords: placemaking, social integration, co-design, socio-spatial, temporary installation

To cite this article:

Ben Othmane Hamrouni, I., Wanas, O. (2020). Placemaking for Coexistence: Child and Community Friendly Space. HOUCH YGAMAANA Project, New Damietta, Egypt, The Journal of Public Space, 5(I), 277-289, DOI I0.3289I/jps.v5il.I262

This article has been peer reviewed and accepted for publication in The Journal of Public Space.

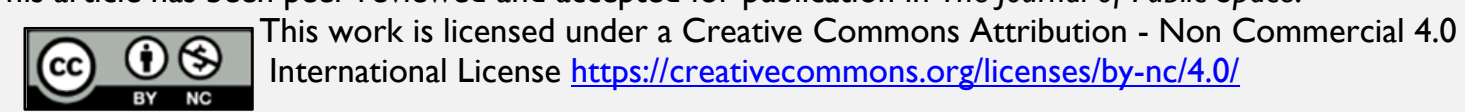

' HOUCH YGAMA'NA: Figurative translates from Arabic as 'A schoolyard for all'. 


\section{Introduction}

HOUCH YGAMA'NA is a participatory 'design and build' project that aims to create age and gender inclusive child-friendly spaces that foster their imagination and enhance their physical, cognitive, emotional and social development and ties. The project was initiated and funded by the UN refugee agency in Egypt UNHCR Community Support Programs unit (CSP) and Terre Des Hommes Egypt and designed and implemented by Ecumene Studio in collaboration with a variety of governmental bodies, universities, architecture students and local civil associations. The project extended from 2014 till 2017 where it was implemented in a total of nine schools (hosting both Syrian and Egyptian students) in Gamasa, Alexandria, Borj El Arab and El Sheikh Zayed and one public park in New Damietta in Egypt . The latter implemented in 2014 will be the focus of this paper.

The New Damietta version of the project entailed a set of urban and design practices centred around a socially engaging installation all aiming to bring the users of the park from the Egyptian and newly settled Syrian Community together to define and participate in reshaping and developing their environment. Through the activities of the project and as a result of the implemented spaces, social bridges are created between the different stakeholders and in particular between the Syrian and Egyptian communities. In addition, The local Syrian community is introduced to one of the active international children rights associations in the area : Terre Des Hommes

\section{Project's Context and Motivation: The "Where" \& "Why":}

New Damietta is located in the North of Damietta governorate and is bound by the Mediterranean Sea from the north, (see figure I). According to the Ministry of New Urban Communities, the population of New Damietta is 135 thousand inhabitants from a total estimated population of 500 thousand. In addition, New Damietta hosts about $8 \%$ (10,923 refugees) of the total Syrian refugees in Egypt, according to UNHCR refugee report in 2014.

Hence, the motivation behind the project was to catalyse the integration and coexistence of this displaced population in their new environment. Furthermore, This version of the project was embedded within Terre Des Hommes's (TDH) program titled "Community Based Child Protection and Psychosocial Support for Displaced Syrian Children and their Families in Damietta". The project brief entailed the design and implementation of a temporary child-friendly outdoor space in a time frame of two months to be a physical component of TDH's outreach strategy for the newly settled Syrian community in New Damietta For the purpose of outreach, The Central Park in New Damietta - of approximate area 54 feddan ${ }^{2}$ - was chosen as the location for the intervention. The Park is publicly and equitably accessible and hosts around 10,000 visitors on public holidays as reported by park administration and is the main gathering point for the residence on a daily basis.

\footnotetext{
I feddan $=1.037$ acres
} 


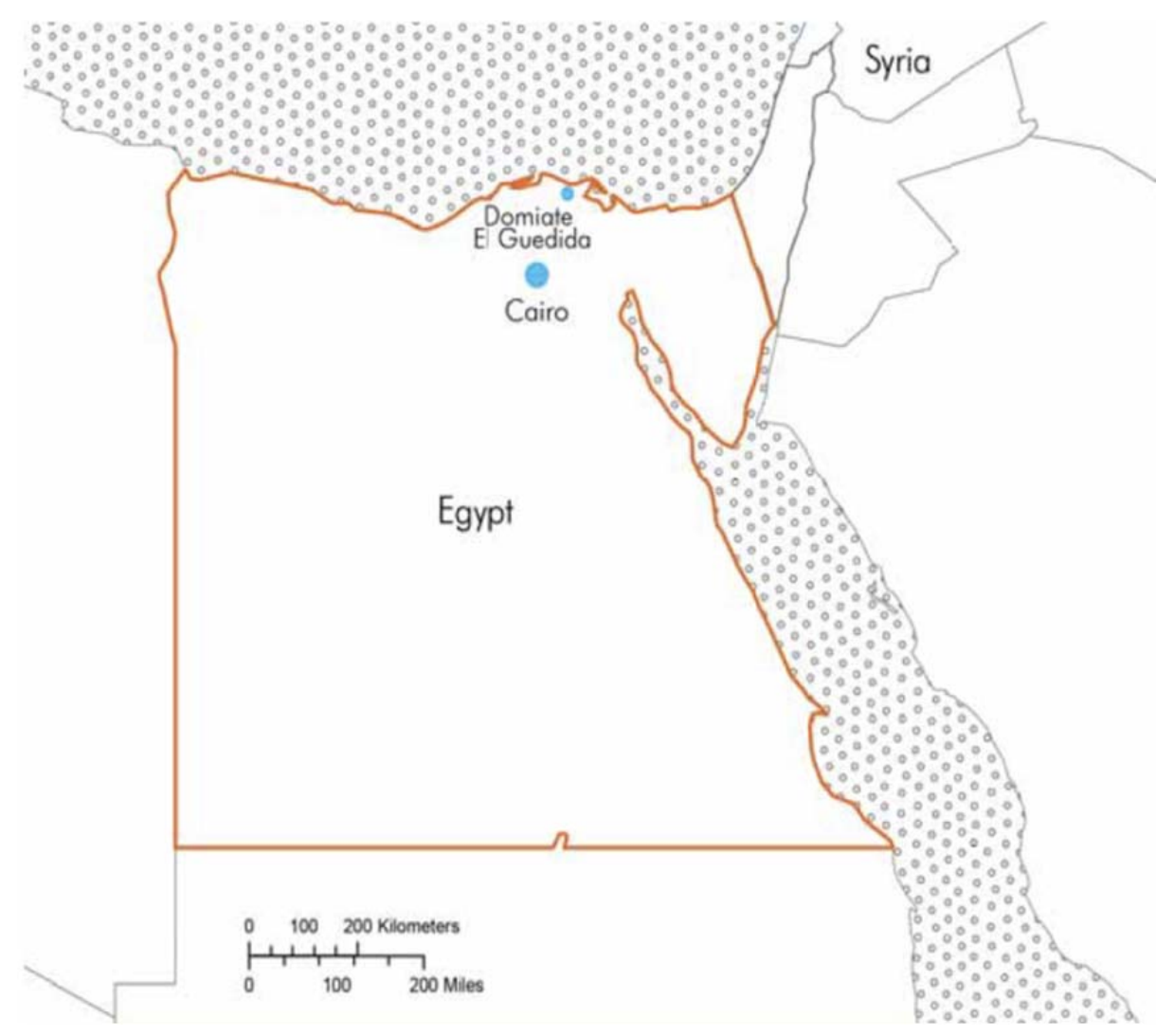

Figure I. Geographic location of New Damietta city, by Author

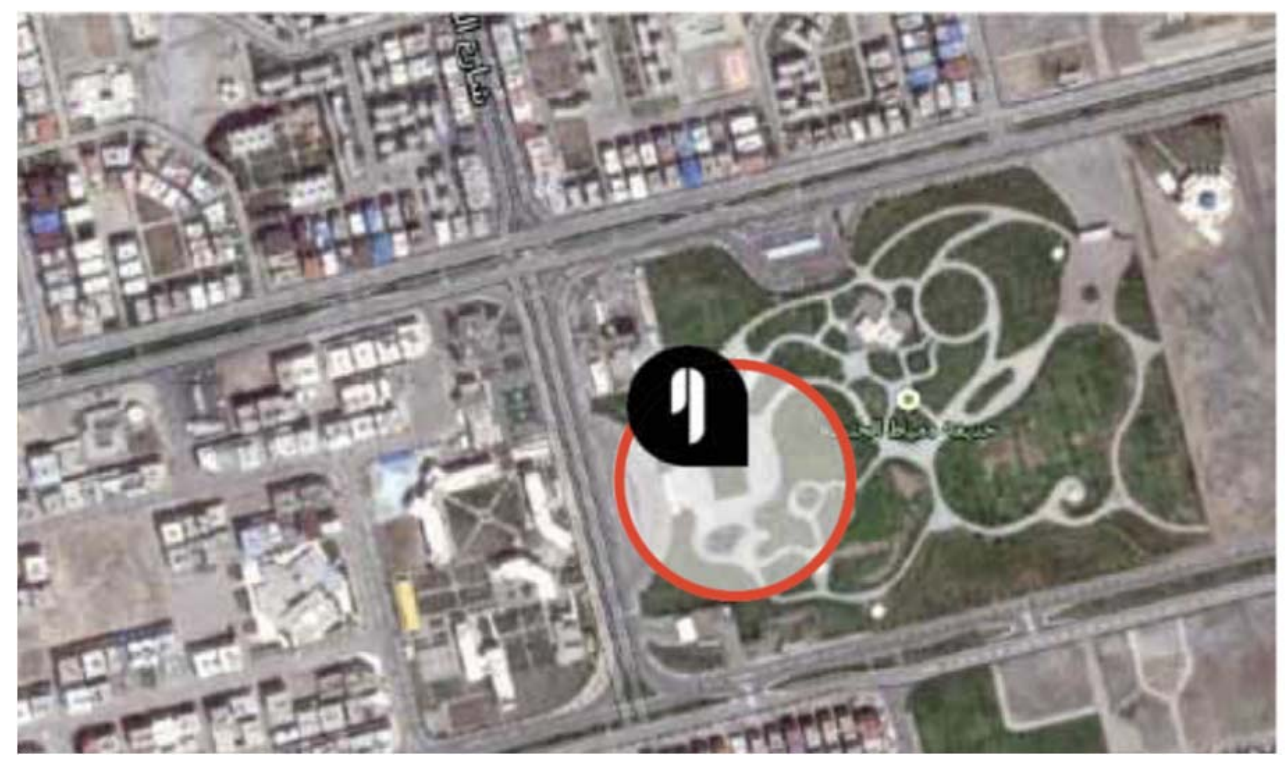

Figure 2. Aerial view of New Damietta's Central Park,Google Maps edited by Author 


\section{Project Methodology: The "How"}

An outreach strategy was developed, so the TDH team could connect with the Syrian community in the city. Brainstorming sessions and site visits were conducted at the beginning of the project to identify stakeholders more likely to be involved in the project and to update the project's plan to determine any needed changes. Through this phase, it was possible to evaluate the needed input from different stakeholders, their interests and how they could contribute to the development of the project.

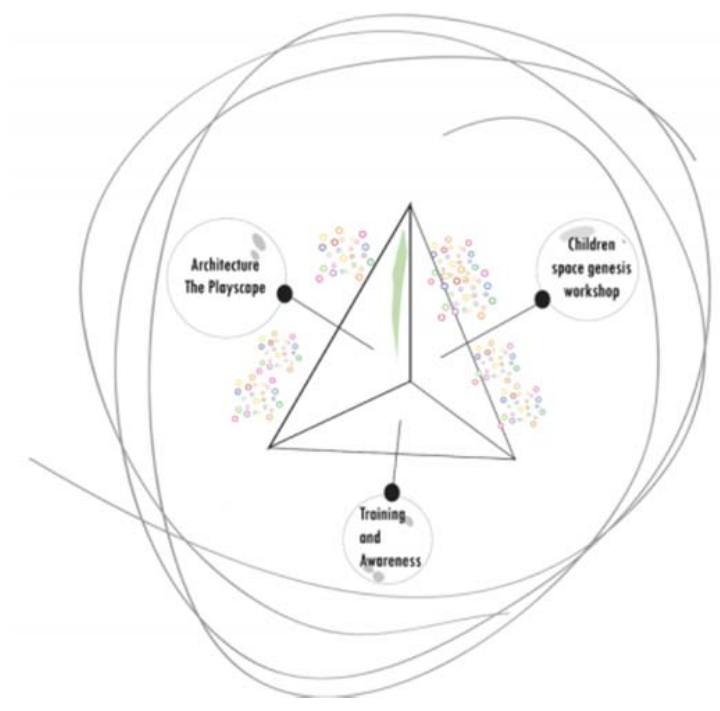

Figure 3. The main components of the project, by Author

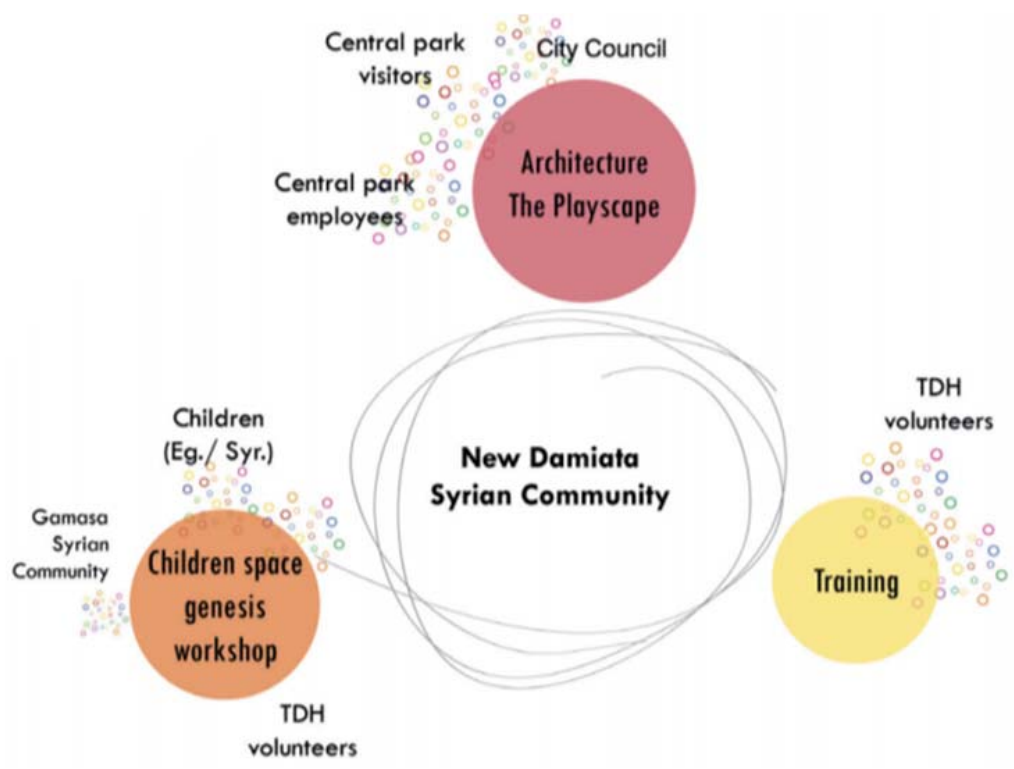

Figure 4. Repartitioning of identified stakeholders according to their interests and mapping their inputs within the project components, by Author 
The participation and support from the local community and users such as children's guardians, families, TDH staff, city council, construction workers, and volunteers was the backbone of the project. This participatory approach manifested itself in a series of workshops that took place through the lifetime of the project:

I. An architecture design and landscape workshop: This workshop was held in participation with the design team, TDH personnel, local craftsmen, the park staff and the city administration. The aim of this workshop was to define the design brief, materials used and the proposed site and location for the project.(Figure 5) .
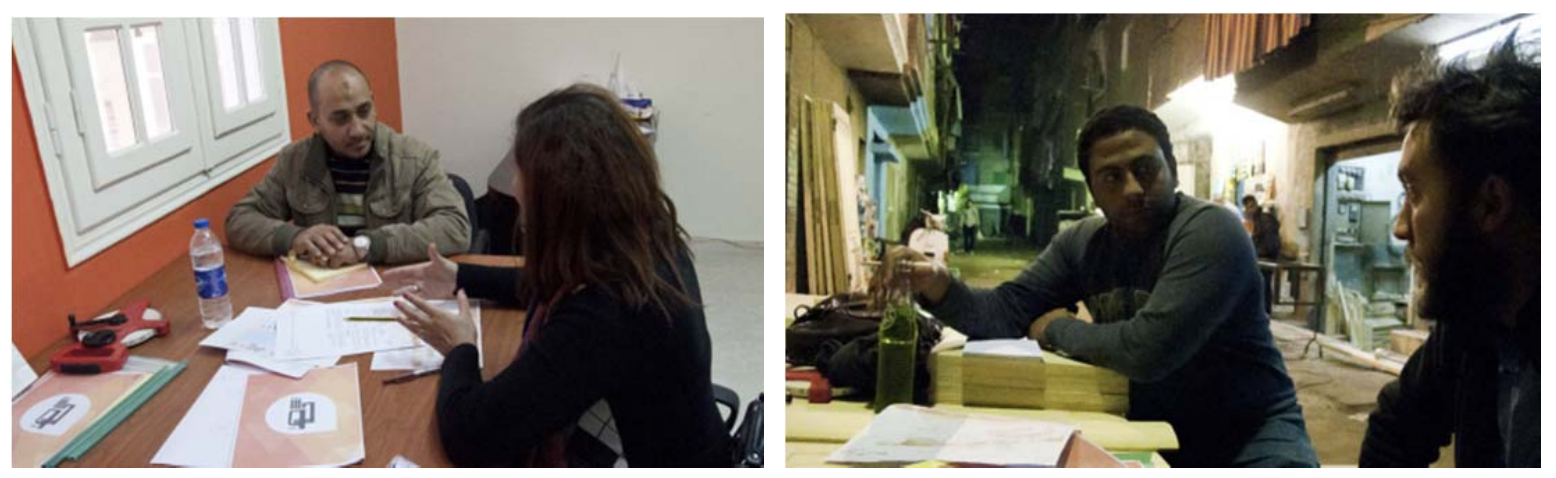

Figure 5. Extracts of the architecture design and landscape workshop, by Author

2. A training and awareness workshop: which took place with the TDH staff and local volunteers with the aim of training them to moderate the space geneses workshop with the children.(Figure 6)
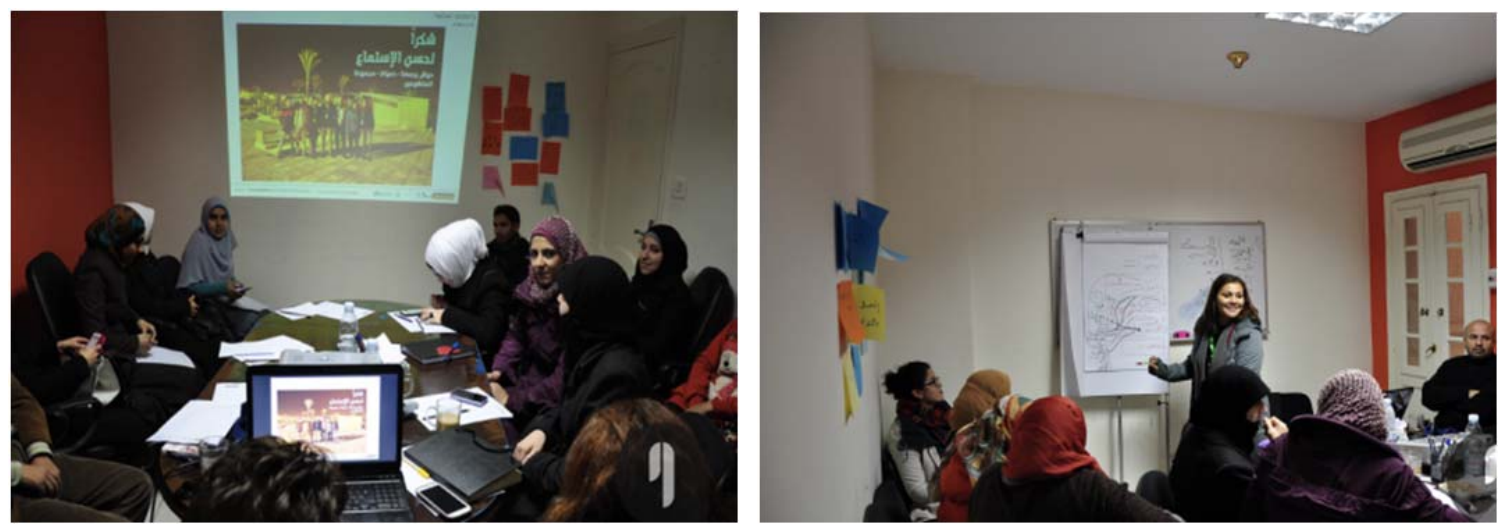

Figure 6. Extracts of the training and awareness workshop, by Author

3. The children space genesis workshop :Including children in plan-ning and design is not a new trend to the field, espe-cially that the UN convention states that "children have the right to be involved in decisions which affect their lives including the empowering ex-perience of contributing to the design of their local environments". In this three-day workshop the children experienced, experimented and re-appropriated the designed space to create a space of their own in the heart of their city. In additional to the physical and social outputs of 
this workshop, TDH personnel had the opportunity to interact with the local Syrian community and became acquainted with the main challenges facing them which would act as a base for several future meetings between both parties (Figure 7).
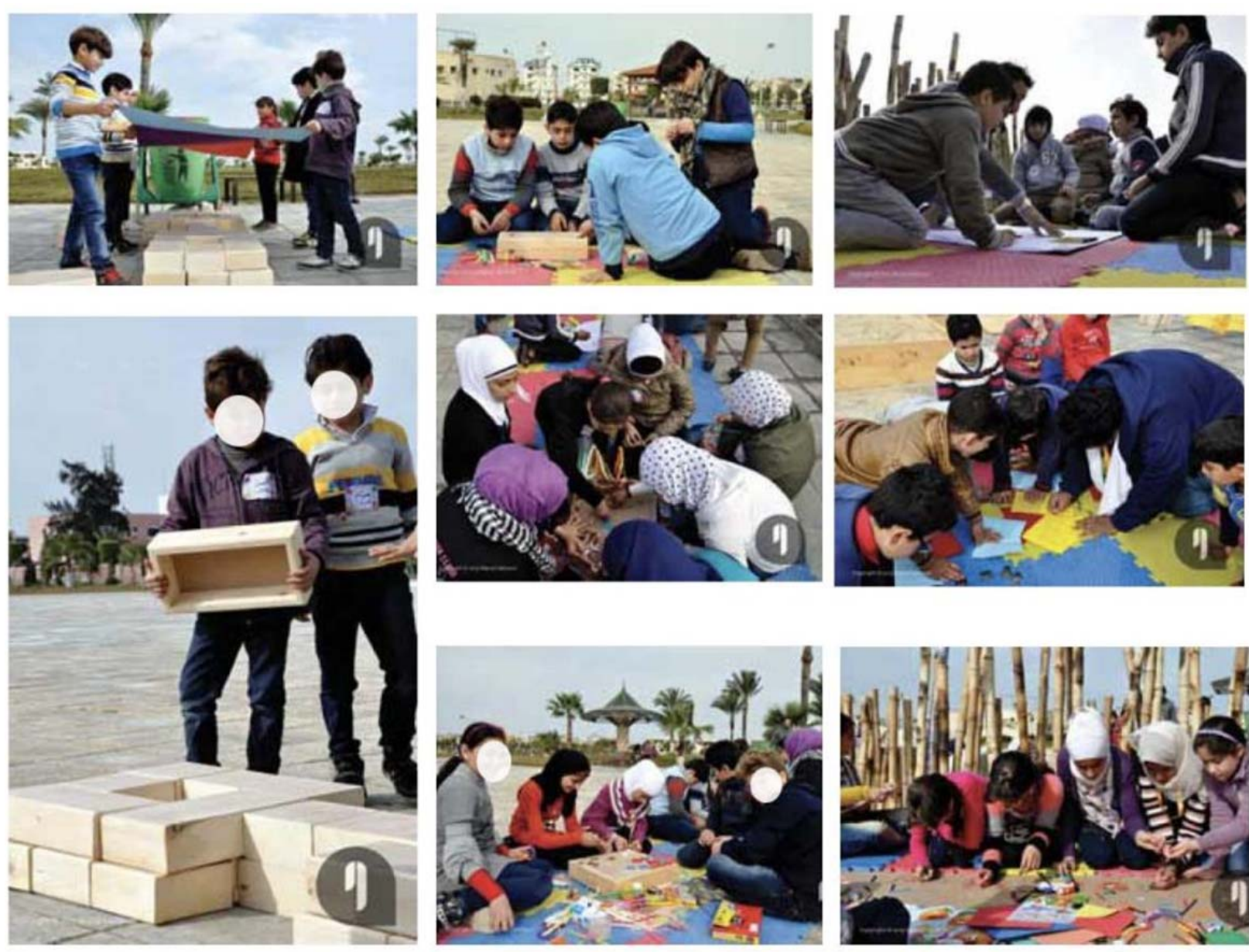

Figure 7. The children space genesis workshop, photo credits: Manal Fakhouri

\section{Project Approach and Design Concepts}

Play may often be looked upon as an unimportant activity or an immature act, (Whitebread, 2012) while play is the only activity by which children can achieve mental, physical, emotional and social development. It is through play that children learn to" solve their own problems, control their own lives, develop their own interests, and become competent in pursuit of their own interests."(Gray, 2010) . Furthermore, DeVries (2006) \& Wilson (2009) classified the various types of play to :Physical play, Play with objects, Symbolic play, Pretense or socio-dramatic play, Games with rules and state that each type aids in the development of certain skills for children. This variety in types of play emphasizes that children should practice all the previous types of play in order to have a healthy childhood experience and be equipped with a set of skills needed for their future life. 
Playscape ${ }^{3}$ - Play + Landscape - is the result of both tangible and intangible items.

"Tangible" refers to physical elements, objects, frames and/or structures. Whereas "Intangible" refers to how these physical elements are used, changed, deconstructed and/or experimented (through learning, playing, movement, etc.). The symbiosis of these two spheres is: the space. Thus, the combination of both physical interventions and activities is essential to create a friendly, healthy and safe space for children, where the child is the only actor to eventually define it. With the aforementioned alterations in mind, the Houch Ygamaana installation was constructed taking the following design concepts within consideration:

a) One space "suits" all

The space was initially designed for children of age 6-12 who are the main participants in the project's Workshop. Yet, the larger spectrum of ages handled by TDH (3- 18) and the context in which the installation exists, called for the design to integrate a larger variety of users: infants, children, youth, parents, the physically challenged and TDH personnel. In the light of the variety of users and the limited space, the single use of a design element was not an option. So, the anthropometric, form, materials, safety measures and distribution of the designed elements, had to serve several purposes. This was achieved through:

- Increasing the width of the seating elements allowing for a variety of ergonomics, positions and activities in addition to seating.

- Adding slopes and adequate space between the elements to act as sliding or jumping platforms.

- Positioning the seats in a setting that allows conversation, community gathering or outdoor learning.

- Placing a large sandbox by the seating area where toddlers can play under their parents' supervision.

- Providing ramps rather than steps as entrances and exits to the installation, with dimensions that accommodate wheelchairs, skates and skateboards.

- designing platforms with varied heights to be challenging for certain ages and fair for others.

- Creating an enclosure that can act as an exhibition, education or a gathering space and also provides space for privacy.

- Adding building blocks, mobile elements and soft ground cover options as an extension of the space when needed for larger groups.

\footnotetext{
${ }^{3}$ https://www.definitions.net/definition/playscape
} 

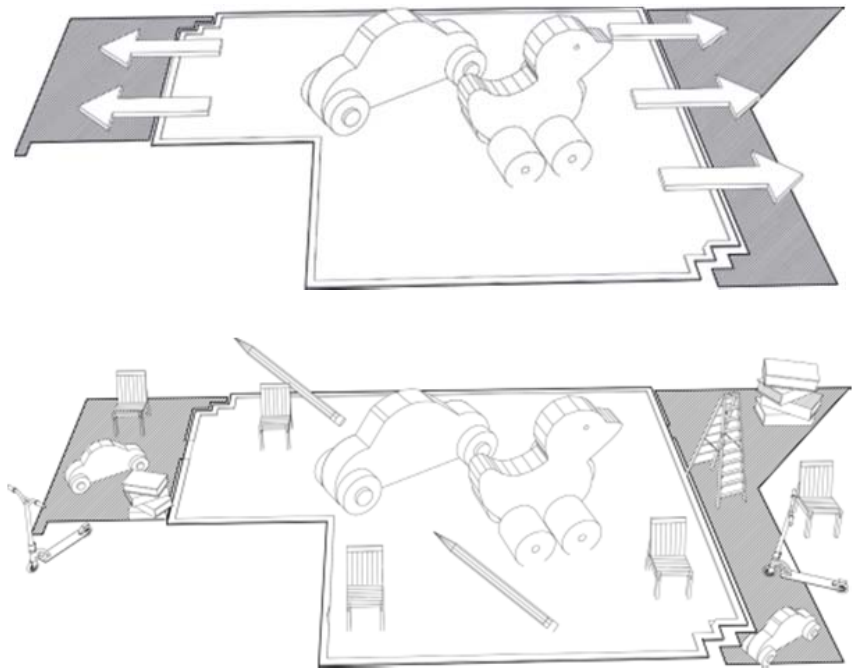

Figure 8.: Conventional approach to playscape (above)VS. The multi-use approach (below), by Author

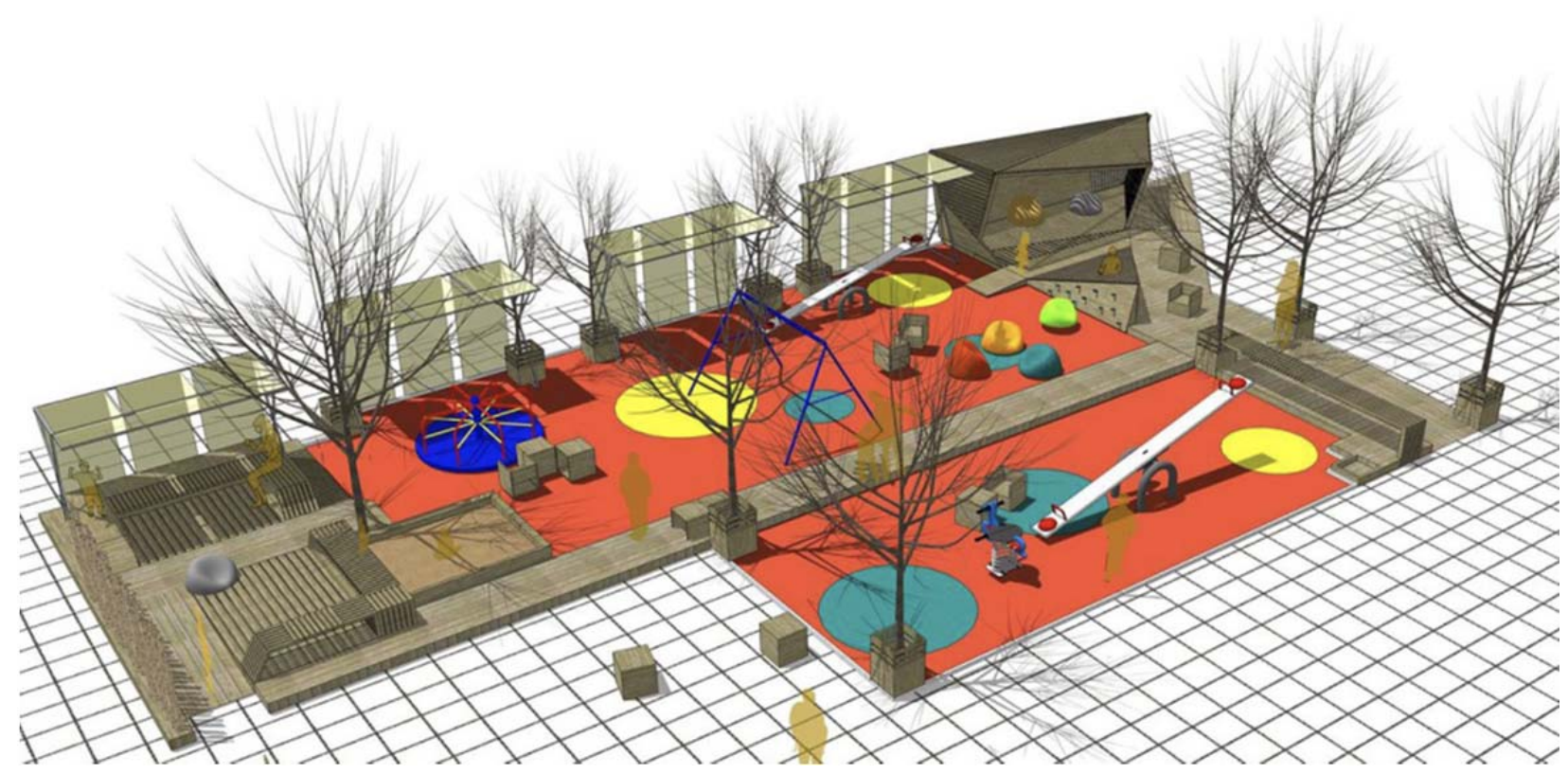

Figure 9. General rendering of Houch Ygamaana installation, by Author

\section{b) Ambiguity for Imagination}

On the contrary to most play spaces in Damietta and Egypt as a whole, The design intentionally lured away from direct symbolization in an attempt not to limit the user's interpretation of the space. Thus, the design encourages the multiuse of the space depending on the will and imagination of the user. The effectiveness of this concept was revealed during the construction period. When the installation was set up, it instantly raised discussions amongst passers-by on its exact function and purpose, some of which perceived it as a stage, a temporary kiosk, a pergola...etc. 
Turning the preceptors of the space from passive to active recipients, not only simulated their imagination but also lead to the emergence of several unplanned activities which in turn induced a sense of control and ownership.

\section{c) A Mobile Structure for A Shifting Space}

Due to the indecision by the local authorities on the final site of the installation and possible relocation in the future, the installation was designed to be modular - rather than site specific - and to facilitate dismantling and transportation. The installation was also designed to evolve according to the user's needs where mobility extended to the design and furnishing elements. Bishop (2000) gives two convincing reasons for "the loose pieces "design concept. The first "...change and novelty is able to stimulate interest and alertness and so children may be much more attentive". The second reason is that "...our senses are designed to monitor changing sensory input, not constant input”.

Therefore, the following items were included in the design:

- A series of 18 mobile cubes that accommodate various uses and activities,

- $\quad 170$ Interlocking rubber floor tiles to provide an alternative soft surface,

- A wood block play kit with repetitive modules and measures for children to create forms and enclosures while playing.

- Eleven colourful bean bags were also provided to allow freedom in the seating arrangement.
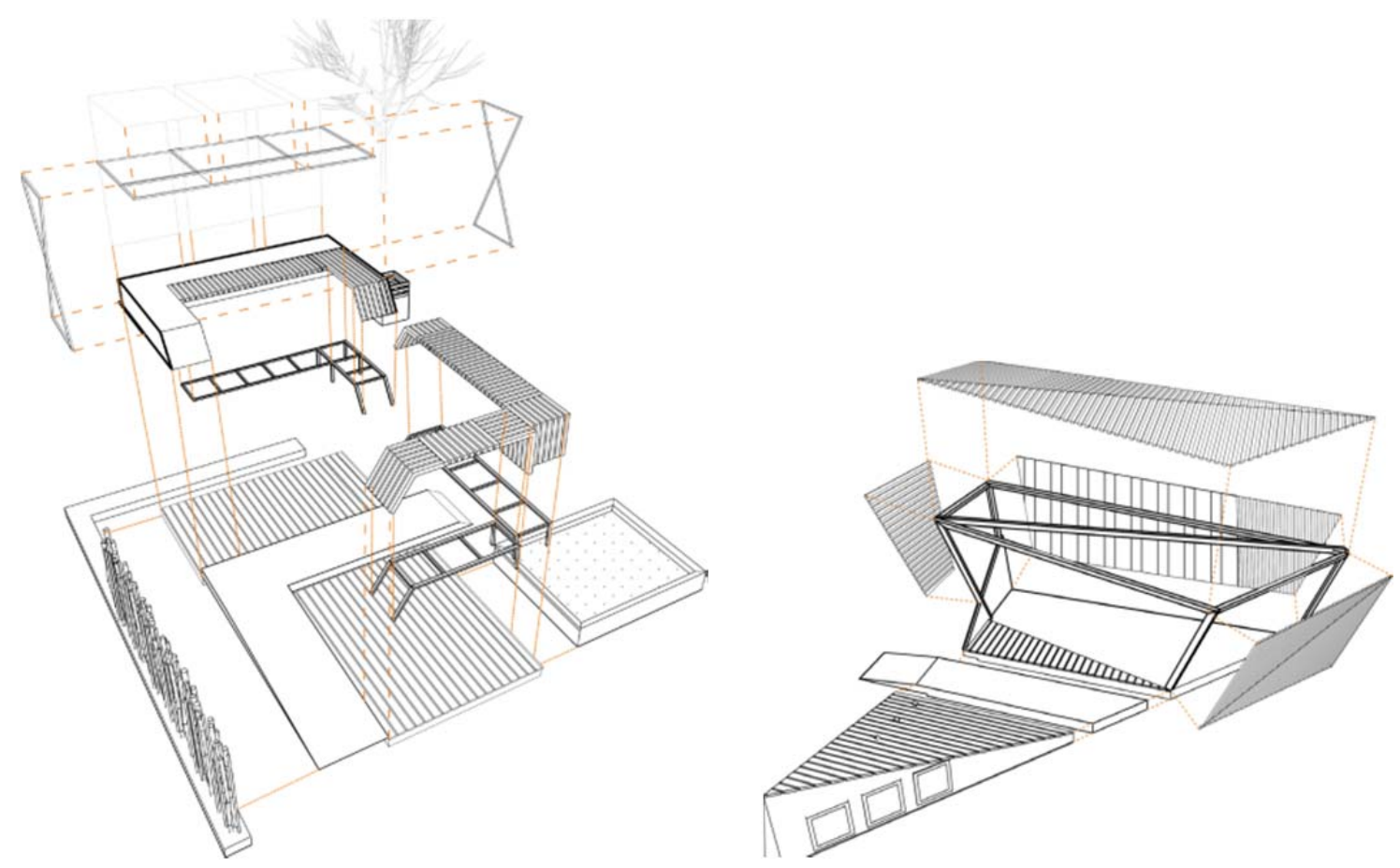

Fig. I0: The dismantling of the installation, by Author 


\section{Lessons Learned and Reflections}

The project was a practical manifestation of the socio-spatial dimension to placemaking where the produced public space is "both a product and producer of change" (Gottdiener M., Hutchison R., 20II) as not only is the created space a collaborative effort by the local community but also a tool within the overall process to achieve the project's overarching goal of TDH to reach vulnerable Syrian residents.

- An inclusive participatory process is vital for the success of projects within the public realm where having several local actors on board from the kickoff of the project aided in facing uncertainty and unexpected obstacles.

- Ambiguity of playscape induces the user's imagination and allows him to form his personal idea about the physical intervention and by so acquire a sense of mental connection with the designed item.

- Flexibility of the design and leaving intentional design gaps to be filled by the users is a key for the physical sustainability of the project as through appropriating the space the user acquires a sense of ownership and bonding with the playscape element and by so decrease the risk of vandalism.

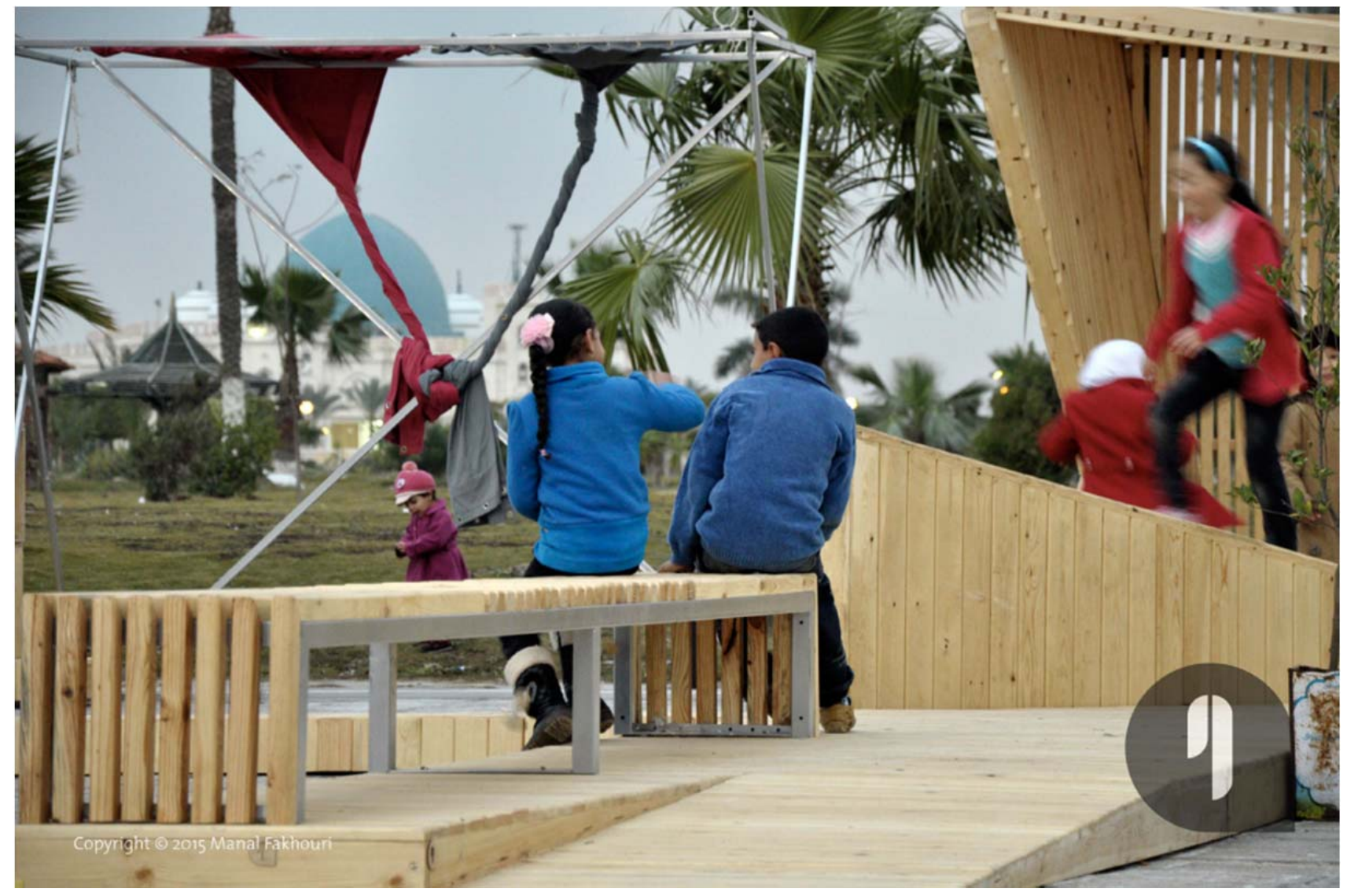

286 | The Journal of Public Space, 5(I), 2020 | ISSN 2206-9658

City Space Architecture / UN-Habitat 

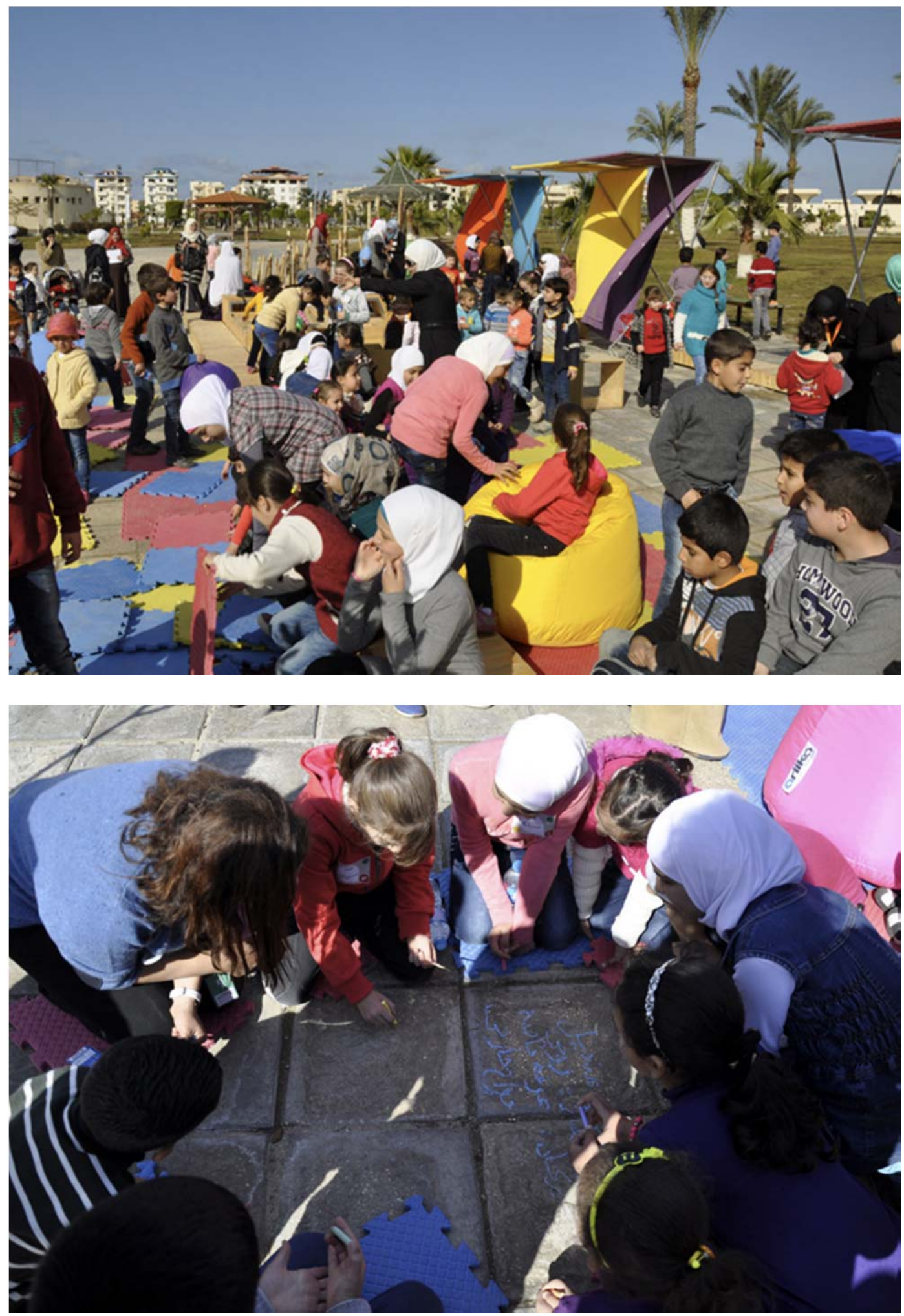

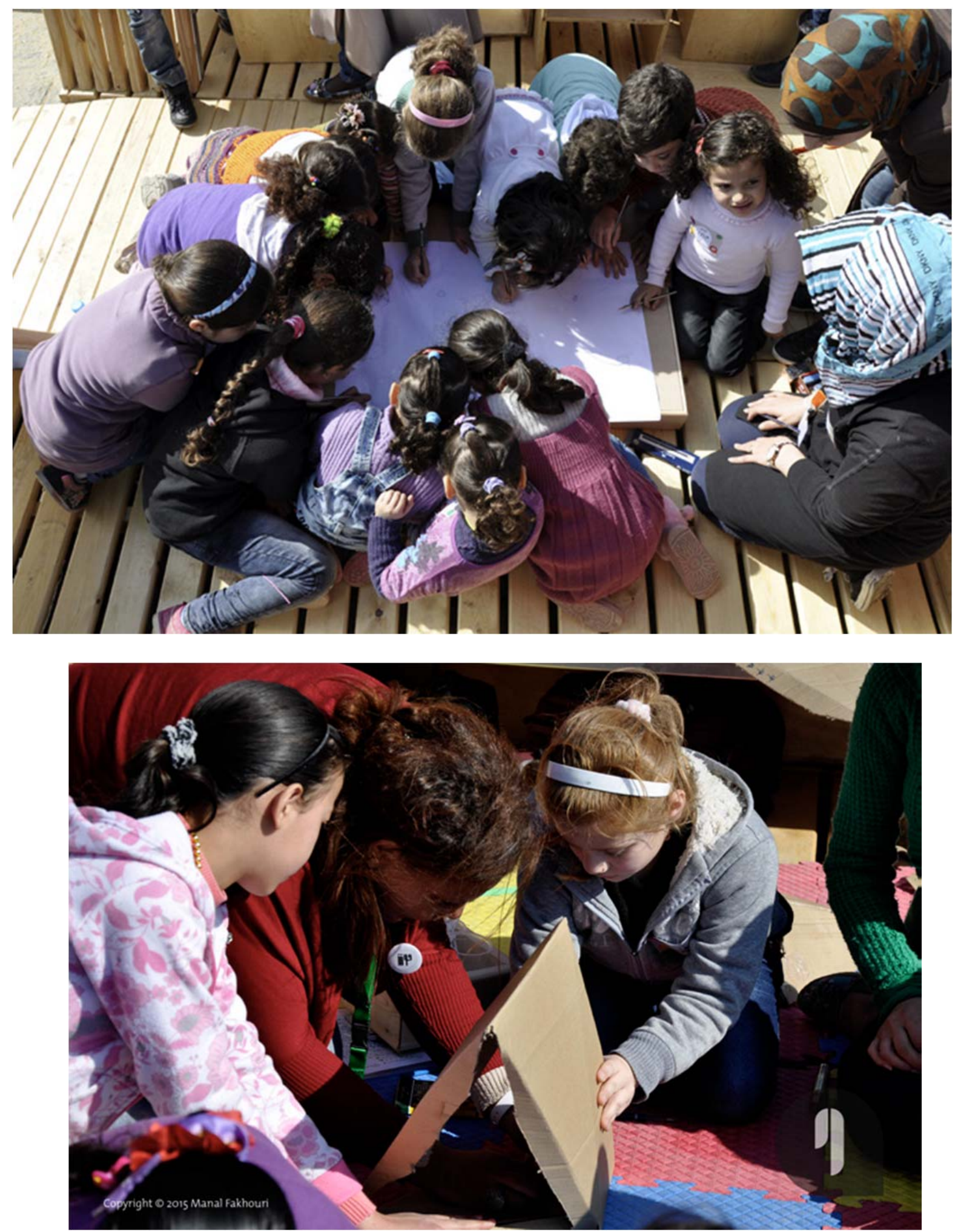

288 | The Journal of Public Space, 5(I), 2020 | ISSN 2206-9658

City Space Architecture / UN-Habitat 


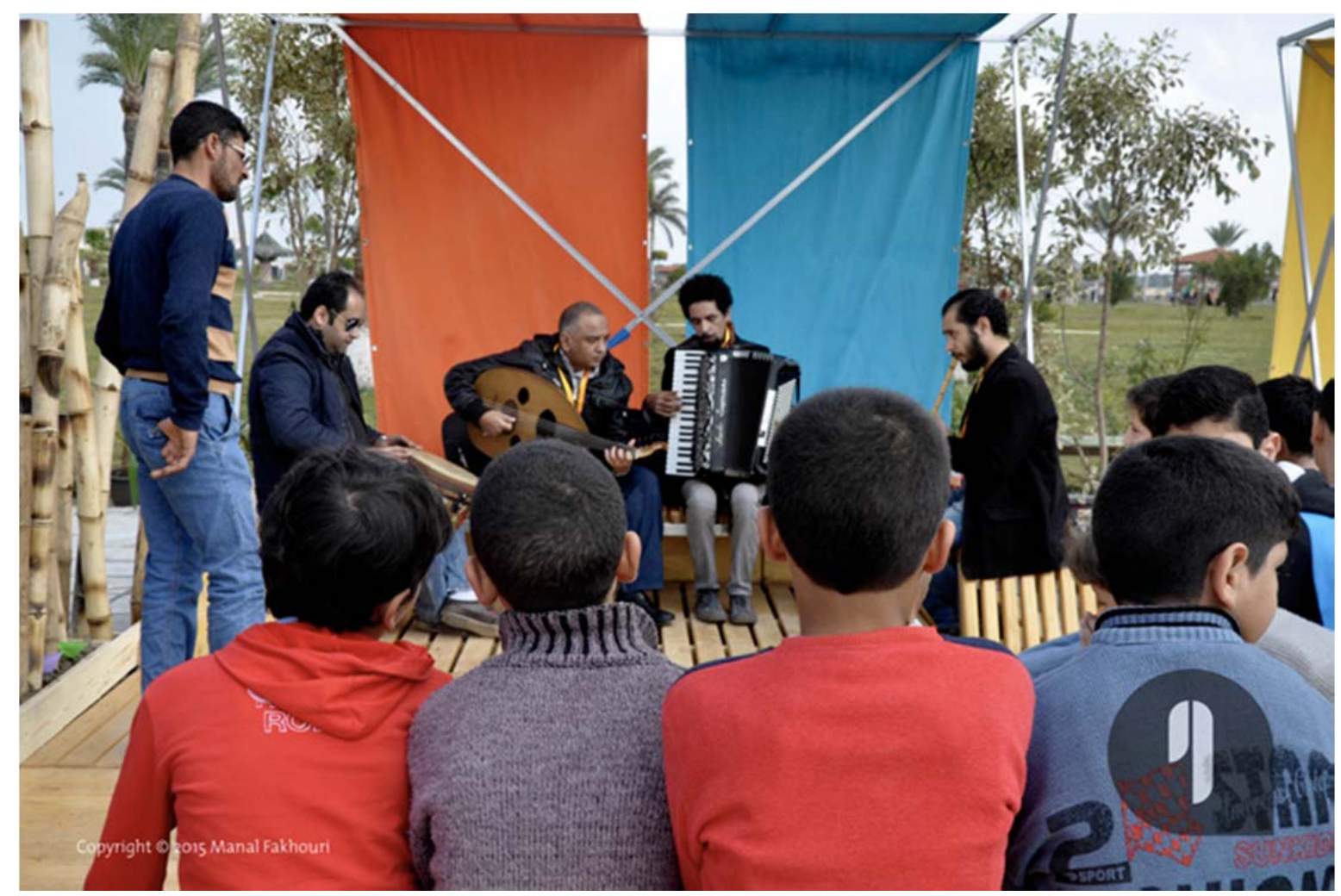

\section{References}

Bishop K., Designing learning environments for all children: Variety and richness, (2000). Available at http:// www.ebility.com/articles/play.php. Accessed: 29 January 2015.

DeVries R., How to Promote Children's Development through Playing Group Games, (2015).

Available at : http://www.uni.edu/coe/regentsctr/publications/Moralandintellect.pdf. Accessed: 2 February 2015.

Gottdiener M. \& Hutchison R. (20II), The New Urban Sociology, 4th ed.

Gray P. (2008). The Value of Play I, Available at: https://www.psychologytoday. Accessed: 2 February 2015.

Gray P. (2010). The Decline of Play and Rise in Children's Mental Disorders, Available at: https://www.psychologytoday.com/blog/freedom-learn/20100I/thedecline-play-andrise-in-childrens-mentaldisorders?collection=160576. Accessed: I February 2015.

Kenedy A. (2009). The Value of Play, A NCAC Factsheet for Families, Australia.

Whitebread D. (20I2). The importance of Play, A report on the value of children's play with a series of policy recommendations, Toy Industry of Europe, University of Cambridge. 